\title{
模拟增温及分解界面对荠草调落物分解速率及叶 际微生物结构和功能的影响
}

\author{
间鹏飞 ${ }^{1}$ 展鹏飞 1 肖德荣 ${ }^{1}$ 王 炏炎 ${ }^{2}$ 余 瑞 刘振亚 $^{1}$ 王 行 ${ }^{*}$ \\ 1西南林业大学国家高原湿地研究中心/湿地学院, 昆明 $650224{ }^{2}$ 云南农业大学农学与生物技术学院, 昆明 650201
}

\begin{abstract}
摘 要 挺水植物的调落物是湿地生态系统物质循环的重要组成部分, 阐明气候变暖以及生境差异对湿地挺水植物调落物 分解过程及叶际微生物的影响对揭示湿地生态系统关键物质循环过程具有重要意义。该研究以滇西北高原典型湿地优势挺水 植物荠草(Zizania latifolia) 为研究对象, 采用调落物袋法研究了荠草在模拟增温 $\left(1.5-2.0{ }^{\circ} \mathrm{C}\right)$ 及不同生境(大气界面、水界面与 土界面)下的质量残留率和叶际微生物数量、结构组成与功能代谢特征。研究发现: 模拟气候变暖及生境差异均显著影响调 落物的分解速率。经过一年的分解, 调落物在模拟增温环境下的质量残留率为 $66.4 \%$, 对照组的质量残留率为 $77.7 \%$, 增温组 分解常数 $(k)$ 值是对照组的 1.64 倍, 而调落物在水界面与土界面的质量残留率为 $42.2 \%$ 和 $25.3 \%$, 其 $k$ 值分别为大气界面的 3.63 和5.25倍, 生境差异是影响湿地挺水植物调落物分解速率的关键因素。模拟增温主要改变了调落物叶际微生物的群落组成特 征, 而生境变化主要影响叶际微生物的绝对数量、微生物多样性、群落结构组成以及功能代谢活性。处于土界面的调落物叶 际微生物具有最高的群落功能代谢活性及醇类碳源利用程度。不同处理之间的植物叶际微生物特征与调落物分解速率具有较 好的一致性, 为揭示湿地植物调落物分解快慢的微生物驱动机制提供了重要的理论依据。
\end{abstract}

关键词 湿地生态系统; 调落物分解; 叶际微生物; 模拟增温; 生境差异

闻鹏飞, 展鹏飞, 肖德荣, 王炏, 余瑞, 刘振亚, 王行 (2019). 模拟增温及分解界面对萃草凋落物分解速率及叶际微生物结构和功能的影响. 植物生态 学报, 43, 107-118. DOI: $10.17521 /$ cjpe.2018.0272

\section{Effects of simulated warming and decomposition interface on the litter decomposition rate of Zizania latifolia and its phyllospheric microbial community structure and function}

YAN Peng-Fei ${ }^{1}$, ZHAN Peng-Fei ${ }^{1}$, XIAO De-Rong ${ }^{1}$, WANG Yi ${ }^{2}$, YU Rui ${ }^{1}$, LIU Zhen-Ya ${ }^{1}$, and WANG Hang ${ }^{1 *}$

${ }^{1}$ Southwest Forestry University National Plateau Wetlands Research Center/Wetlands College, Kunming 650224, China; and ${ }^{2}$ College of Agronomy and Biotechnology, Yunnan Agricultural University, Kunming 650201, China

\begin{abstract}
Aims Litters of emergent plants are important components of material cycling in wetland ecosystems. To clarify the effects of climate warming and habitat difference on the litter decomposition processes and phyllospheric microorganisms of wetland emergent plants is of great significance for revealing the key material cycling processes in wetland ecosystems.

Methods Zizania latifolia, a dominant emergent plant in typical wetlands of Northwestern Yunnan Plateau, was chosen for this study. Using litter bag methods, we studied mass remaining and the abundance, community structure and metabolic potential of phyllospheric microorganisms of the litter from Zizania latifolia under simulated warming $\left(1.5-2.0^{\circ} \mathrm{C}\right)$ and under three habitats (air, water and soil interface).

Important findings Simulated climatic warming and habitat difference significantly affected the litter decomposition rate. After one-year decomposition, the mass remaining of litter was $66.4 \%$ under the simulated warming treatment, while $77.7 \%$ under the control treatment. The decomposition constant $(k)$ value was 1.64 times under warming compared to the control. The mass remaining of litter at the water and soil interface was $42.2 \%$ and $25.3 \%$, and the $k$ value at the water and soil interface was 3.63 and 5.25 times of that at the air interface respectively. These results indicate that habitat difference was the key factor controlling the decomposition of emergent plant litter in wetlands. Moreover, warming mainly changed the community composition of litter phyllospheric microorganisms, while decomposition interface mainly affected the abundance, community structure and meta-

收稿日期Received: 2018-10-31 接受日期Accepted: 2019-01-30

基金项目：国家自然科学基金(41877346、31500409和41867059)。Supported by the National Natural Science Foundation of China (41877346, 31500409 and 41867059).

* 通信作者Corresponding author (hwang17@163.com)
\end{abstract}


bolic potential of phyllospheric microorganisms. Notably, phyllospheric microorganisms of litter at soil interface had the highest metabolic potential and utilized alcohols as main carbon sources. The characteristics of phyllospheric microorganisms between different treatments were in good agreement with litter decomposition rate, which provides an important theoretical basis for revealing the microbial mechanisms driving the decomposition of wetland plant litter.

Key words wetland ecosystem; litter decomposition; phyllospheric microorganisms; simulated warming; habitat difference

Yan PF, Zhan PF, Xiao DR, Wang Y, Yu R, Liu ZY, Wang H (2019). Effects of simulated warming and decomposition interface on the litter decomposition rate of Zizania latifolia and its phyllospheric microbial community structure and function. Chinese Journal of Plant Ecology, 43, 107-118. DOI: 10.17521/cjpe.2018.0272

调落物是指由地上植物组分产生并归还到地表, 且作为分解者的物质与能量来源，在维持生态系统 结构与功能方面发挥着重要作用的所有有机质的总 称(王凤友, 1989; 彭少麟和刘强, 2002)。凋落物分解 作为全球碳收支的一个重要组成部分, 是陆地生态 系统物质循环和能量流动的重要环节, 其分解速率 的高低直接影响着生态系统物质循环以及土壤有机 质的形成过程(Berg \& McClaugherty, 1989)。温度及 生境差异被认为是影响调落物分解的主要因子, 微 生物是驱动调落物分解的关键引擎(孙志高和刘景 双, 2007)。近年来随着全球气候变暖, 调落物分解 速率不断加快, 深刻影响着陆地生态系统的物质循 环和能量流动过程(Marty et al., 2015)。因此, 在全 球气候变化背景下评估温度升高、生境差异对调落 物分解速率的影响, 以及调落物分解背后的微生物 驱动机制, 能够为揭示陆地生态系统碳循环过程提 供重要的科学依据。

在时间尺度上, 气候变暖是调控调落物分解的 主要因素; 在空间尺度上, 调落物分解主要受到所 处环境中水热因子的调控, 表现出较大的异质性 (徐振锋等, 2009; 李强等, 2014)。未来全球变化背景 下, 气候变暖和生境特征将协同影响凋落物分解速 率, 然而两者对调落物分解的驱动力大小以及对生 态系统物质循环的贡献程度还有待明确。当前绝大 多数调落物分解研究主要集中在森林生态系统(徐 振锋等, 2009; 李强等, 2014; 唐仕姗等, 2014)。有关 湿地生态系统中植物调落物分解的报道较少。挺水 植物作为湿地生态系统碳循环的核心载体, 其调落 物分解速率是影响湿地生态系统碳收支的关键(郭 绪虎等, 2013)。在全球气候变化背景下, 温度作为 生态代谢理论的核心要素之一, 将显著影响调落物 分解的过程及强弱, 进而引起生态系统结构与功能 的一系列变化(宋飘等, 2014)。未来气候变暖很可能
通过改变调落物分解的强度, 影响我国及全球范围 的碳收支平衡(徐小峰等, 2007)。

微生物是调落物分解的关键驱动者(李姗姗等, 2016)。微生物与调落物分解之间的关系是调落物研 究领域的热点, 也是广泛争议的焦点(宋影等, 2014)。当前, 调落物分解过程中的物理、化学过程 研究较为透彻, 然而受调落物分解生境的影响, 调 落物叶际微生物呈现出各异的数量、群落组成及功 能代谢特征, 导致人们对调落物分解过程的微生物 机制认知不足。尤其是湿地挺水植物调落物叶际微 生物的研究还鲜有报道, 微生物在调落物分解中所 扮演的角色还没有达成普遍共识(黄锦学等, 2010; 陈亚梅等, 2015)。湿地挺水植物的生存特征以及调 落物存在状态往往有别于陆生植物, 植物死亡后, 其地上部分不会立即倒伏, 而是保持立枯状态并持 续一段时间, 立枯阶段的植物残体与大气接触, 受 大气温、湿环境的调控。如处于空气中分解的立枯 物, 其调落物表面的 $\mathrm{CO}_{2}$ 释放表现出明显的昼夜周 期性, 受昼夜温度与湿度生境下微生物作用的联合 影响(Kuehn et al., 2004)。随着死亡时间的延长, 植 物残体倒伏后与水体、土壤直接接触, 表现出不同 于立枯阶段的分解速率以及水-热环境特征(王亿慧 等, 2015)。在整个过程中微生物扮演重要角色, 在 立枯阶段, 大量微生物侵入植物残体, 植物的分解 和矿化过程已经开始(Newell, 2001)。挺水植物死亡 进入水体之后, 外源营养物质的输入将进一步刺激 叶际微生物的生长与繁殖, 随后土壤中的微生物会 逐渐侵入植物残体, 加速植物的分解(杨秀虹等, 2013), 然而在整个过程中有关微生物的变化并不 清楚。与此同时, 未来气候变化也将会通过影响调 落物表面微生物数量、群落组成及功能特征, 进而 影响调落物分解速率。因此, 在未来气候变化大背 景下, 增温与生境差异对调落物分解影响的强弱程 
度还有待明确。特别是凋落物叶际微生物响应未来 气候变化以及生境差异的群落学特征尚不清楚。

本文的研究地点位于滇西北高原香格里拉生态 观测站，该区域地处青藏高原东南缘横断山区，具 有封闭与半封闭的区域特征, 对气候变化高度敏 感。艾草(Zizania latifolia)为多年生宿根型草本植物, 是该区域优势挺水植物的典型代表。伴随植物地上 部分死亡，荠草调落物存在明显的立枯、倒伏、沉 水等不同分解阶段, 能较好地反映绝大多数湿地挺 水植物死亡后的分解状态。结合IPCC (2013) 预测结 果, 通过开顶式生长室(OTC)模拟气候变暖(增温幅 度为 $\left.1.5-2.0{ }^{\circ} \mathrm{C}\right)$ 。同时, 将调落物分别放置在大气界 面、水界面及土界面等不同生境中开展分解实验, 研 究在模拟增温实验与生境差异实验下: (1)调落物分 解季节性动态变化; (2)调落物叶际微生物菌落数量; (3)微生物群落结构多样性及物种组成; (4)微生物功 能代谢特征。通过研究调落物分解速率、叶际微生 物特征变化, 分析关键因子(温度及生境)对湿地植物 调落物分解的趋异影响, 为进一步揭示湿地生态系 统碳收支过程提供微生物学机理解释及理论依据。

\section{1 材料和方法}

\section{1 研究区概况}

研究区位于迪庆州香格里拉市 $\left(27.82^{\circ}-27.92^{\circ}\right.$ $\left.\mathrm{N}, 99.62^{\circ}-99.68^{\circ} \mathrm{E}\right)$, 地处滇西北高原、横断山脉中 段, 平均海拔3 $260 \mathrm{~m}$ 。该区域属于寒温带高原季风 气候带, 具有高寒、冷湿及干湿季分明的气候特征。 每年6-9月为雨季, 其他月份为旱季, 年平均气温 $5.40{ }^{\circ} \mathrm{C}$, 年降水量 $619.9 \mathrm{~mm}$ 。最冷月平均气温 $-3.81{ }^{\circ} \mathrm{C}$, 最热月平均气温 $13.2{ }^{\circ} \mathrm{C}, \geqslant 10{ }^{\circ} \mathrm{C}$ 积温 $1529{ }^{\circ} \mathrm{C}$ 。滇西北高原属气候变化敏感区, 该区域在 过去50年间的平均气温升高了 $1.32{ }^{\circ} \mathrm{C}$, 显著高于全 国同期平均水平(Fan et al., 2011)。滇西北高原湿地 以纳帕海湿地为典型代表, 区域内共发现 4 个草甸 群落、6 个挺水植物群落、 2 个浮叶植物群落以及 3 个沉水植物群落, 优势挺水植物主要包括艾草、黑 三棱(Sparganium stoloniferum) 及杉叶藻 (Hippuris vulgaris)等。

\section{2 实验材料制备}

于植物生长末期(2014年10月中旬), 在纳帕海 湿地湖滨带收集荠草的地上部分, 迅速带回实验 室。首先进行自然风干(1周), 并仔细剔除植物表面
的泥土与碎石块, 用牛皮纸包裹样品后放入烘箱, 为便于水蒸气透过, 牛皮纸顶部包裹较为松散并留 有部分开口, 在 $65.0{ }^{\circ} \mathrm{C}$ 条件下处理 $48 \mathrm{~h}$ 至恒质量。 取出后将植物剪成 $10 \mathrm{~cm}$ 左右长度的小段, 制作成 茎、叶混合的调落物样品, 称质量后放入预制的尼 龙网袋中(孔径 $1 \mathrm{~mm}$, 宽 $10 \mathrm{~cm}$, 长 $15 \mathrm{~cm}$ ), 每袋精 确放入 $5.00 \mathrm{~g}$ 调落物。

\section{3 调落物分解实验}

实验方案见图1, 包括模拟增温实验与生境差 异实验。模拟增温实验主要利用香格里拉生态观察 站内的开顶式生长室(Open-top Chamber, OTC)对实 时温度进行增温模拟, 研究荠草调落物在模拟增温 环境下的分解速率。结合湿地挺水植物特有生活型, 生境差异实验主要将调落物袋放置于大气界面、水 界面与土界面, 研究调落物在不同自然生境中的分 解速率。具体处理方法为: 将调落物袋通过PVC管 悬于空中 $1.2 \mathrm{~m}$ 处(大气界面), 通过在调落物袋中放 入乒乓球使调落物袋悬浮于水中(水界面)和将调落 物袋掩埋在 $5.0 \mathrm{~cm}$ 深度的底泥中(土界面)。控制因素 包括两种温度处理(对照组与增温组)以及三种生境 处理(大气界面、水界面以及土界面), 每个处理设置 3 个重复。2014年12月将制备好的调落物袋放置于不 同处理中。2015年全年开展野外分解实验, 共分 5 次 回收调落物袋。模拟增温实验设置 30 个调落物袋 $(2$ 种温度 $\times 3$ 个重复数 $\times 5$ 个采样时间节点), 生境差异 实验设置 45 个调落物袋 $(3$ 种生境 $\times 3$ 个重复数 $\times 5$ 个 采样时间节点)。将每次取回的调落物自然风干一周 后, 仔细剔除泥土和碎石块等, 于 $65.0{ }^{\circ} \mathrm{C}$ 烘箱内放 置 $48 \mathrm{~h}$ 至恒质量, 用电子天平称质量。同时, 在分解 末期(2015年12月), 测定调落物叶际微生物菌落数、 群落结构组成以及功能代谢特征, 研究不同处理下 的叶际微生物差异特征, 探讨微生物对调落物分解 的驱动机制。

调落物的分解程度用质量残留率 $(E)$ 值来表征:

$$
E(\%)=M_{\mathrm{t}} / M_{\mathrm{o}} \times 100 \%
$$

式中, $M_{\mathrm{o}}$ 为调落物初始质量 $(\mathrm{g}), M_{\mathrm{t}}$ 为调落物分解后的 剩余质量 $(\mathrm{g})$ 。E值越大, 分解量越少; $E$ 值越小, 分解 越彻底。

利用指数衰减模型计算分解常数 $(k)$ 值:

$$
M_{\mathrm{t}} / M_{\mathrm{o}}=\mathrm{e}^{-k t}
$$

式中, $t$ 为分解时间。 $k$ 值越大, 分解速率越快; $k$ 值越 小, 分解速率越慢。 

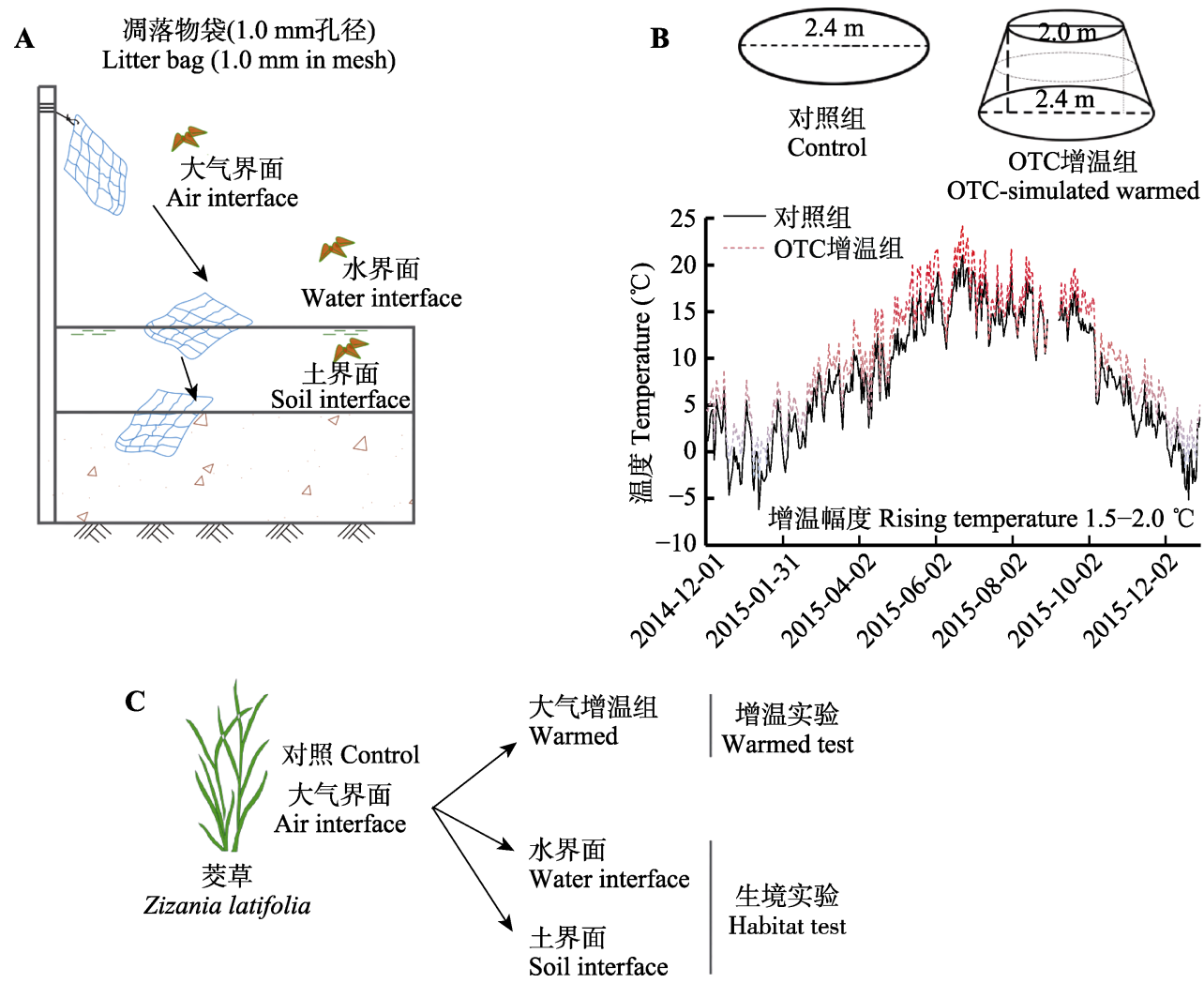

图1 荠草调落物分解模拟增温与生境差异实验。 $\mathbf{A}$, 三种生境包括大气界面、水界面以及土界面。其中, 大气界面中的调落 物袋悬于PVC管上方距离地面 $1.2 \mathrm{~m}$ 处; 水界面中的调落物袋中放入乒乓球使调落物袋始终悬浮于水中; 土界面中的调落物 袋通过PVC管将其固定在 $5.0 \mathrm{~cm}$ 掩埋深度的底泥中。 $\mathbf{B}$, 开顶式生长室 $(\mathrm{OTC})$ 的设计及运行。其中, 对照组无OTC装置, OTC增 温组以直径为 $2.4 \mathrm{~m}$ 的底座以及直径为 $2.0 \mathrm{~m}$ 的开口所设计建造的阳光板为材料, 实现大气增温模拟。2014年12月至2015年12 月全年实时采集 $\left(1\right.$ 次 $\left.\cdot \mathrm{h}^{-1}\right)$ 对照组与 OTC增温组中的气温数据, 实现 $1.5-2.0{ }^{\circ} \mathrm{C}$ 温度增幅。 $\mathbf{C}$, 研究对象为湿地挺水植物荠草的 叶调落物，包括增温实验和生境差异实验(其中增温实验对照组和生境差异实验中大气界面的样品相同)。

Fig. 1 Experiment of simulated warming and habitat difference for litter decomposition of Zizania latifolia. A, Three habitats include air interface, water interface, and soil interface. Among them, litter bags under air decomposition were hang over the bamboo ( $1.2 \mathrm{~m}$ from the ground), litter bags under water decomposition were floated in the surface of water (with the aids of table tennis), and litter bags under soil decomposition were fixed by PVC tubes in the soils $(5.0 \mathrm{~cm}$ in deep). B, The design and operation of Open-top Chamber (OTC). Among them, control group has no OTC devices, and OTC devices simulate rising temperature (warming group). The device was constructed by solar panels with $2.4 \mathrm{~m}$ base and $2.0 \mathrm{~m}$ opening in diameter. The temperatures between control and warming groups were recorded from December 2014 to December 2015 (once per hour). In warming treatment, the temperature has been raised by $1.5-2.0^{\circ} \mathrm{C}$. C, The research object was a typical emergent wetland plant, Zizania latifolia. Its leaf litter was subjected to warming and habitat difference treatments.

\section{4 微生物菌落计数}

称取相当于 $1.0 \mathrm{~g}$ 烘干凋落物的新鲜凋落物, 放 入装有 $9 \mathrm{~mL}$ 无菌水的离心管中, 在超声波清洗仪中 超声处理 $20 \mathrm{~min}$ 后放至摇床振荡 $30 \mathrm{~min}$, 转速为 250 $r \cdot \min ^{-1}$ 。在 $4{ }^{\circ} \mathrm{C}$ 冰箱内静置 $10 \mathrm{~min}$ 后, 在超净工作台 中稀释 20 倍, 取 $100 \mu \mathrm{L}$ 稀释液在平板计数琼脂制成 的培养基上进行平板涂布, 涂布完成后, 将培养基 置于恒温培养箱, 在 $37{ }^{\circ} \mathrm{C}$ 条件下培养 $24 \mathrm{~h}$ 后进行微 生物菌落计数。

\section{5 微生物群落结构组成分析}

称取相当于 $2.0 \mathrm{~g}$ 烘干调落物的新鲜调落物, 放 置于预冷的磷酸缓冲盐溶液 $\left(10 \mathrm{mmol} \cdot \mathrm{L}^{-1}, \mathrm{pH}=7.2\right)$
中, 放入钢珠颗粒, 恒温培养振荡器振荡 $30 \mathrm{~min}$, 之后在超声波清洗器中以 $40 \mathrm{~W}$ 的功率清洗 $10 \mathrm{~min}$, 静置30 min后收集沉淀在瓶底的沉淀物。对沉淀物 用Power Soil DNA Isolation Kit提取总DNA并通过 $0.8 \%$ 琼脂糖凝胶电泳检测其完整性。同时，利用 Nanodrop 2000c检测DNA的质量。对提取的DNA样 品进行细菌16S rRNA基因的PCR扩增。扩增引物为 338F (ACTCCTACGGGAGGCAGCAG) 和 806R (GACTACHVGGGTWTCTAAT)。PCR反应条件为: $98{ }^{\circ} \mathrm{C}$ 预变性 $3 \mathrm{~min} ; 98{ }^{\circ} \mathrm{C}$ 变性 $30 \mathrm{~s}, 50{ }^{\circ} \mathrm{C}$ 退火 $30 \mathrm{~s}$, $72{ }^{\circ} \mathrm{C}$ 延伸 $30 \mathrm{~s}, 27$ 个循环; $72{ }^{\circ} \mathrm{C}$ 恒温 $5 \mathrm{~min}$ 。电泳 PCR 产物使用 AxyPrepDNA 凝胶回收试剂盒 
(AXYGEN公司)进行切胶回收纯化, 之后根据电泳 初步定量结果, 将回收纯化的 PCR 产物用 QuantiFluorTM-ST 蓝色苂光定量系统 (Promega, USA)进行检测定量。根据定量结果和测序量要求, 取PCR产物构建测序文库。构建好的文库在Illumina Miseq PE300测序平台上进行测序操作。测序结果利 用 Quantitative Insights Into Microbial Ecology (QIIME)平台进行分析(Caporaso et al., 2010)。首先 对双向序列进行拼接, 检查其中存在测配错误的序 列, 去除嵌合体序列, 得到高质量的序列进行下一 步分析。根据UCLUST按照 $97 \%$ 相似性将全部基因 序列聚类, 去除singleton的Operational Taxonomic Unit (OTU), 得到代表性 OTU序列。利用软件 Mothur中的 summary.single命令, 计算微生物物种 的丰富度(Chao1)指数, 同时将代表性OTU序列与 Ribosomal Database Project (RDP)参考数据库对比, 得到物种在属水平的分类信息。

\section{6 微生物功能代谢特征分析}

利用 Biolog 微生物全自动鉴定与分析系统 (Biolog, Hayward, USA), 对微生物功能代谢特征进 行分析(王珍等, 2017)。称取相当于 $1.0 \mathrm{~g}$ 烘干调落物 的新鲜调落物, 加入到装有 $4 \mathrm{~mL}$ 生理盐水的离心管 中, 在超声波清洗仪中超声处理 $20 \mathrm{~min}$ 后放至摇床 振荡 $30 \mathrm{~min}$, 转速为 $250 \mathrm{r} \cdot \mathrm{min}^{-1}$ 。在 $4{ }^{\circ} \mathrm{C}$ 冰箱内静置 10 min后, 稀释至100倍, 将其接种到Biolog GENIII 板上, 在温度 $28{ }^{\circ} \mathrm{C}$ 、空气湿度 $25 \%$ 、无光照的恒温 培养箱中培养, $168 \mathrm{~h}$ 内每隔 $12 \mathrm{~h}$ 取出GENIII板, 测 定样品吸光值 $(O D$ 值)用来反映微生物对相应碳源 的利用程度。Biolog GENIII板的71种单一碳源可分 为六大类: 糖类 $(24$ 种 $)$ 、氨基酸类(10种)、醇类 $(5$ 种 $)$ 、

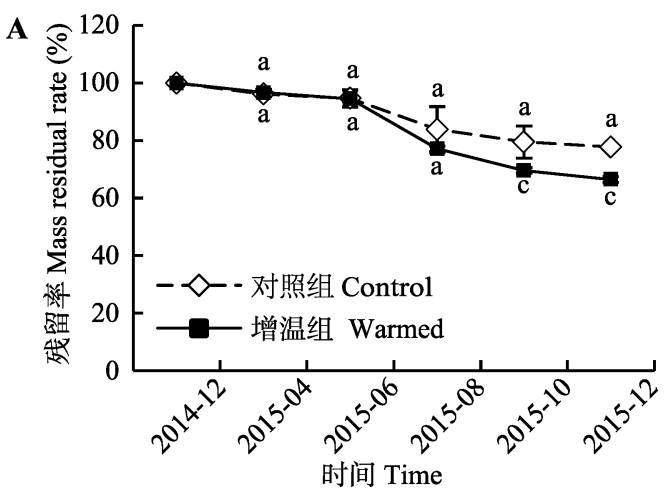

胺类 $(5$ 种 $)$ 、酯类 $(4$ 种 $)$ 和酸类( 23 种)。

测定 GENIII 板 71 种碳源的平均颜色变化率 (AWCD), 用来描述土壤微生物群落的整体代谢活 性, 绘制12-168 h内的微生物代谢活性动态变化曲 线。通过Gompertz生长模型对曲线进行参数拟合:

$$
y=a \mathrm{e}^{-\mathrm{e}^{\left(-k\left(x-X_{c}\right)\right)}}
$$

式中, $x$ 为培养时间( $\mathrm{h}), y$ 为 $A W C D$ 值。拟合参数包括 $a, X_{c}$ 以及 $k$ 值。其中 $a$ 为曲线最大值, 用来反映微生 物对碳源利用的程度; $X_{c}$ 为曲线拐点, 用来反映微 生物对碳源利用的速率; $k$ 为曲线形状参数。

将微生物对碳源的利用程度按照六大类碳源进 行划分, 除以碳源个数后得到均一化后的微生物对 每类碳源的利用百分数值。同时, 利用Past 3.0软件 中的相似性分析研究不同处理之间碳源利用的差异 特征, 量化不同碳源对差异的贡献度大小。

\section{2 结果}

\section{1 调落物残留率的季节性变化}

与对照组相比, OTC模拟增温显著提高了艾草 叶调落物的分解速率 $(p<0.01$, 图 $2 \mathrm{~A})$ 。经过一年的 分解, 对照组荠草的质量残留率为 $77.7 \%(k=0.056)$, 增温组荠草的质量残留率为 $66.4 \%(k=0.092)$ 。生境 差异对荠草叶调落物的分解速率也具有显著影响 $(p$ $<0.001$ ), 不同生境下的分解速率表现为土界面 $>$ 水 界面 $>$ 大气界面(图2B)。经过一年的分解, 对照组荠 草在土界面的残留率仅为 $25.3 \%(k=0.294)$, 在水界 面的残留率为 $42.4 \%(k=0.203)$, 而在大气界面的残 留率高达 $77.7 \%(k=0.056)$ 。在不同分解界面下, 调 落物所处生境的异质性对分解速率具有显著影响 (图2B)。

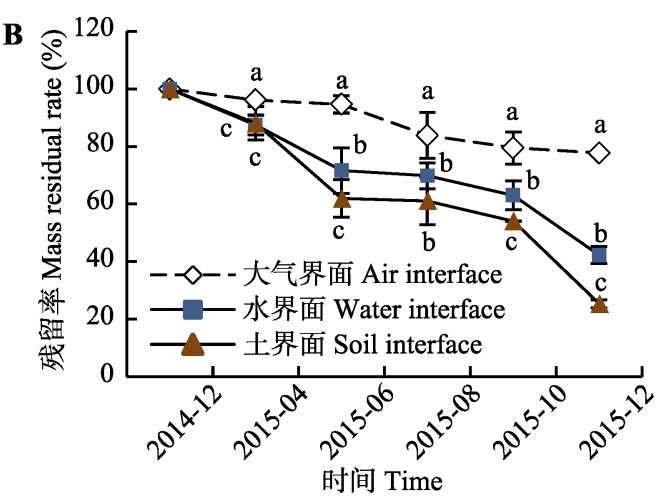

图2 荠草叶调落物质量残留率的季节性动态(平均值沶准误差, $n=3$ )。利用Post Hoc Tests进行两两比较分析, 不同小写字母 代表处理之间的差异达到显著水平 $(p<0.05)$ 。

Fig. 2 Seasonal dynamics in mass remaining of leaf litter from Zizania latifolia (mean $\pm S E, n=3$ ). The different lowercase letters above error bars indicate significant differences between treatments by Post Hoc Tests $(p<0.05)$. 


\section{2 微生物菌落数统计}

通过可培养方式获得单位叶调落物(干基质量) 附着微生物的菌落数(CFU)。分析发现, 增温组叶际 微生物群落绝对数量略低于对照组(低 $29.6 \%$, 图3A), 气候变暖有降低凋落物叶际微生物数量的趋势, 但 两者之间差异不显著 $(p>0.05)$ 。随着调落物从大气 界面进入水界面、土界面, 其表面栖息微生物的绝对 数量显著增加, 从图 $3 \mathrm{~B}$ 可以看出, 处于水界面与土 界面的叶际微生物菌落数分别为 $30.8 \times 10^{6}$ 以及 36.5 $\times 10^{6} \mathrm{CFU} \cdot \mathrm{g}^{-1}$, 是大气界面叶际微生物菌落数量的

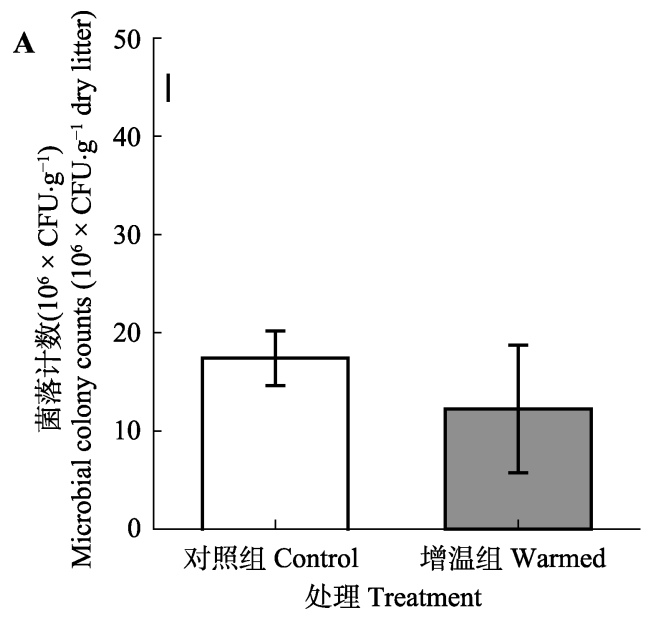

\subsection{7 和 2.10 倍。}

\section{3 微生物多样性及群落结构组成特征}

通过Chao1指数对比研究微生物丰富度在不同 处理之间的差异性(图4)。与对照组相比, 增温处理 下的调落物叶际微生物丰富度略高于对照组, 但差 异不显著 $(p>0.05)$ 。与大气界面与水界面相比, 处 于土界面的调落物叶际微生物丰富度更高 $(p<0.05)$, 其Chao1指数是大气界面的 2.01 倍, 是水界面的 2.39 倍。然而，大气界面与水界面之间的差异不显著 $(p>$ $0.05)$ 。

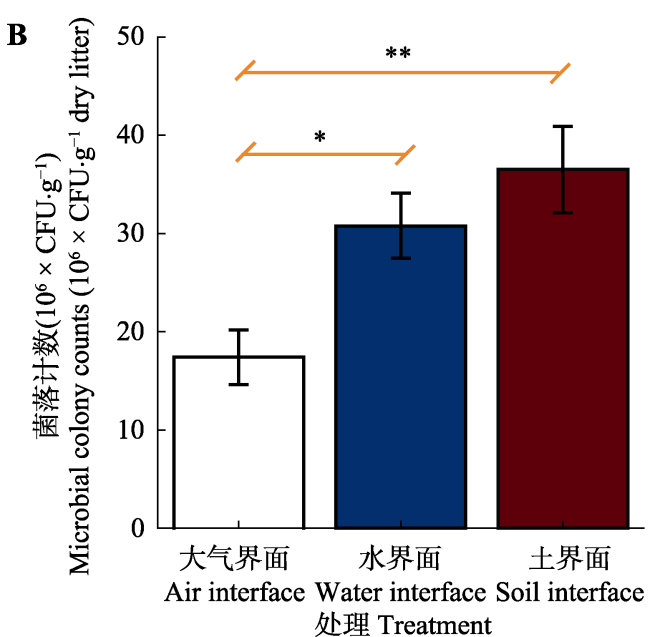

图3 荠草调落物叶际微生物菌落平板计数(平均值土标准误差)。 ${ }^{*}, p<0.05 ; * *, p<0.01$ 。

Fig. 3 Microbial colony counts in culture dish for leaf litter of Zizania latifolia (mean $\pm S E$ ). *, $p<0.05$; **, $p<0.01$.
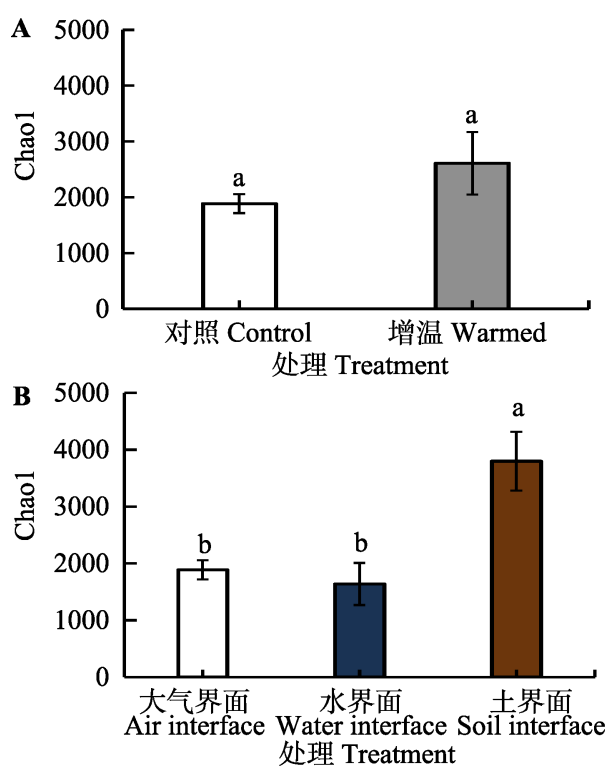

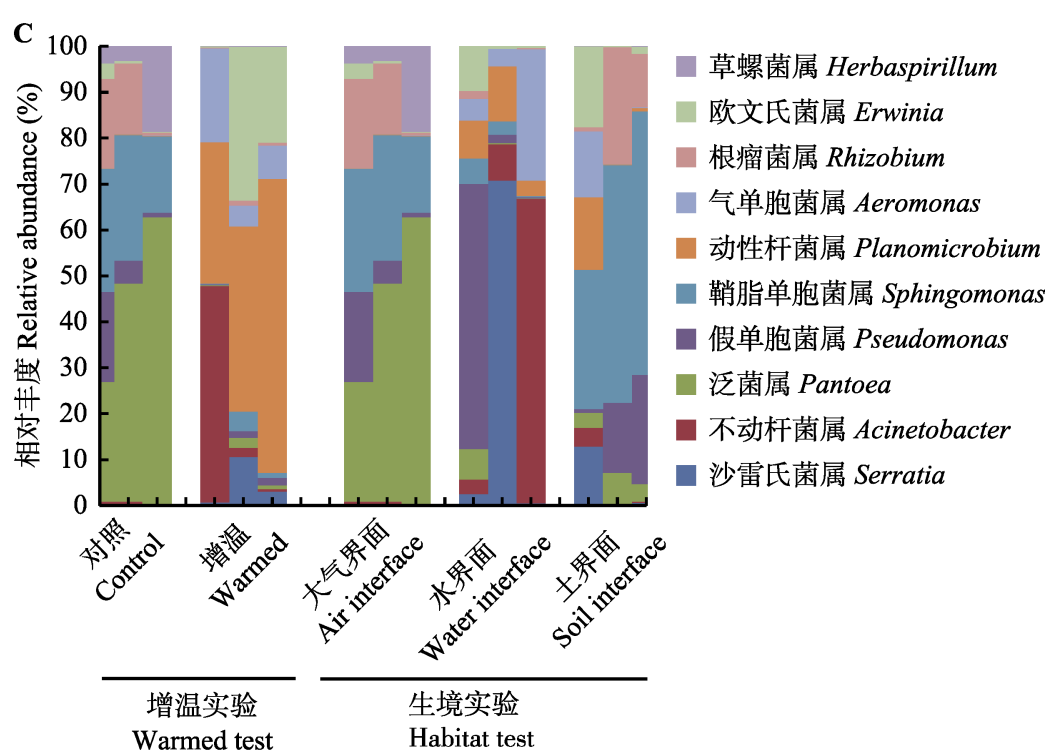

图4 荠草调落物叶际细菌群落多样性指数(Chao1)及细菌在属分类水平上的群落结构特征。图中误差线为标准误差 $(n=3)$, 利用Post Hoc Tests进行两两比较分析，不同小写字母代表处理之间的差异达到显著水平 $(p<0.05)$ 。

Fig. 4 Diversity of bacterial community indicated by Chaol index and the bacterial community composition at the genus level for leaf litter of Zizania latifolia. The error bars represent standard errors $(n=3)$, and the different lowercase letters above error bars indicate significant differences between treatments by Post Hoc Tests $(p<0.05)$.

www.plant-ecology.com 
进一步在属水平研究了微生物群落组成的差异性 (图4C)。在对照组中, 泛菌属(Pantoea)为优势种, 而 在增温条件下, 优势种转变为动性杆菌属 (Planomicrobium)。侵入水体的调落物, 其不同重复 样品之间叶际微生物的分布规律具有很大的随机性, 3 个重复样品的优势菌落分别为假单胞菌属(Pseudomonas)、沙雷氏菌属(Serratia)以及不动杆菌属 (Acinetobacter)。处于土界面的叶际微生物优势种为 鞘脂单胞菌属(Sphingomonas)。可见，气候变暖与生 境变化均改变了调落物叶际微生物的群落组成结 构。

\section{4 微生物功能代谢特征}

$A W C D$ 值反映了微生物对不同碳源的整体代谢 活性。从图 5 可以看出, 培养初期为对数增长期, $A W C D$ 值变化较快, 微生物对碳源利用的活性逐渐 提高, 随着培养时间延长, $96 \mathrm{~h}$ 后 $A W C D$ 值增长缓慢 且逐渐趋于稳定。增温处理下的微生物碳源整体代 谢活性略高于对照组, 但差异不显著 $(p>0.05)$ 。不 同界面之间, 土界面观测到的 $A W C D$ 值在整个观测 阶段内(12-168 h) 显著高于大气界面和水界面 $(p<$

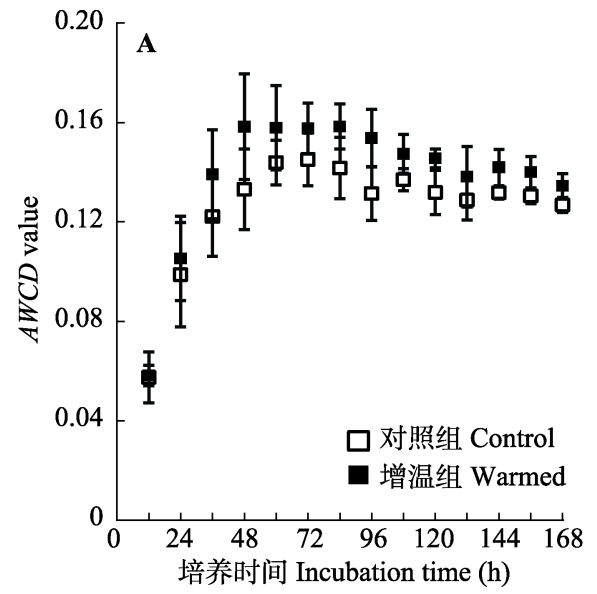

$0.05)$, 而大气界面与水界面之间的差异不显著 $(p>$ 0.05)。我们进一步通过Gompertz生长模型对曲线进 行拟合，获取拟合参数。分析发现，土界面的 $A W C D$ 动态曲线的 $a$ 值为 0.182 , 显著高于大气界面 $(a=$ $0.135)$ 和水界面 $(a=0.136)(p<0.05)$, 表明处于土界 面的调落物叶际微生物对碳源代谢的利用程度最 高。水界面 $A W C D$ 动态曲线的 $X_{c}$ 值为 10.99 , 略高于 大气界面 $\left(X_{c}=10.63\right)$ 与土界面 $\left(X_{c}=9.82\right)$, 表明处于 水界面的调落物叶际微生物对碳源代谢的利用速度 最快。

在六大类碳源中(图6), 利用程度最高的碳源主 要为氨基酸类、醇类和胺类, 微生物对脂类的利用 程度最低。不同处理之间，微生物对六大类碳源的 利用只有细微差异。较为明显的差异主要体现在对 醇类碳源的利用上, 即处于水界面、土界面的微生 物对醇类碳源的利用率较高。进一步通过SIMPER 分析, 研究了造成不同处理之间代谢差异的关键碳 源(图7)。造成对照组与增温组微生物代谢差异的关 键碳源主要为糖类、氨基酸类、醇类和胺类碳源，对 差异贡献度最高的碳源主要包括龙胆二糖、蔗糖、

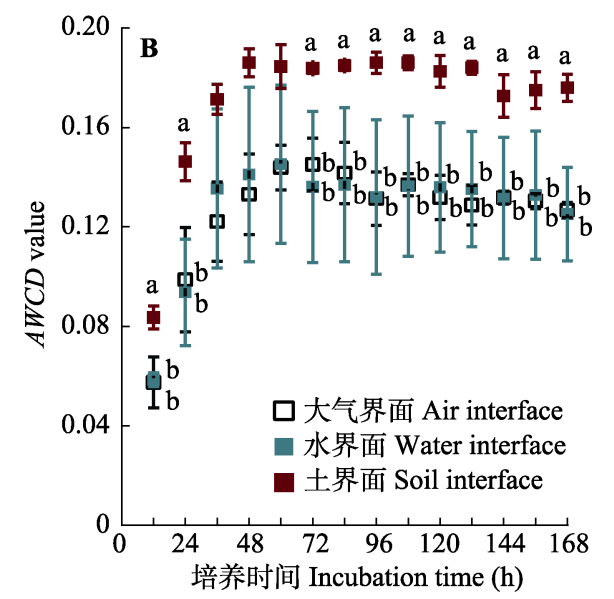

图5 荠草调落物叶际微生物碳源利用的平均颜色变化率 $(A W C D)$ 值动态变化(培养时间为 $12-168 \mathrm{~h}$ )。图中误差线为标准误差 $(n=3)$, 利用Post Hoc Tests进行两两比较分析, 不同小写字母代表处理之间的差异达到显著水平 $(p<0.05)$ 。

Fig. 5 Dynamics in average well color development (AWCD) value for carbon sources utilized by litter phyllospheric microorganisms of Zizania latifolia during an incubation period of $12-168 \mathrm{~h}$. The error bars represent standard errors $(n=3)$, and the different lowercase letters above error bars indicate significant differences between treatments by Post Hoc Tests $(p<0.05)$.
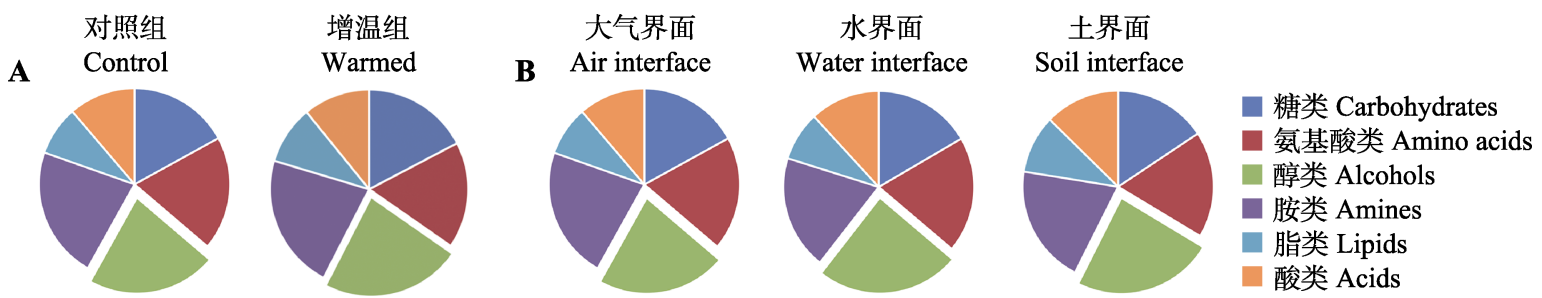

图6 荠草调落物叶际微生物对六大类碳源的利用情况。

Fig. 6 Utilization of six major groups of carbon sources by litter phyllospheric microorganisms of Zizania latifolia. 

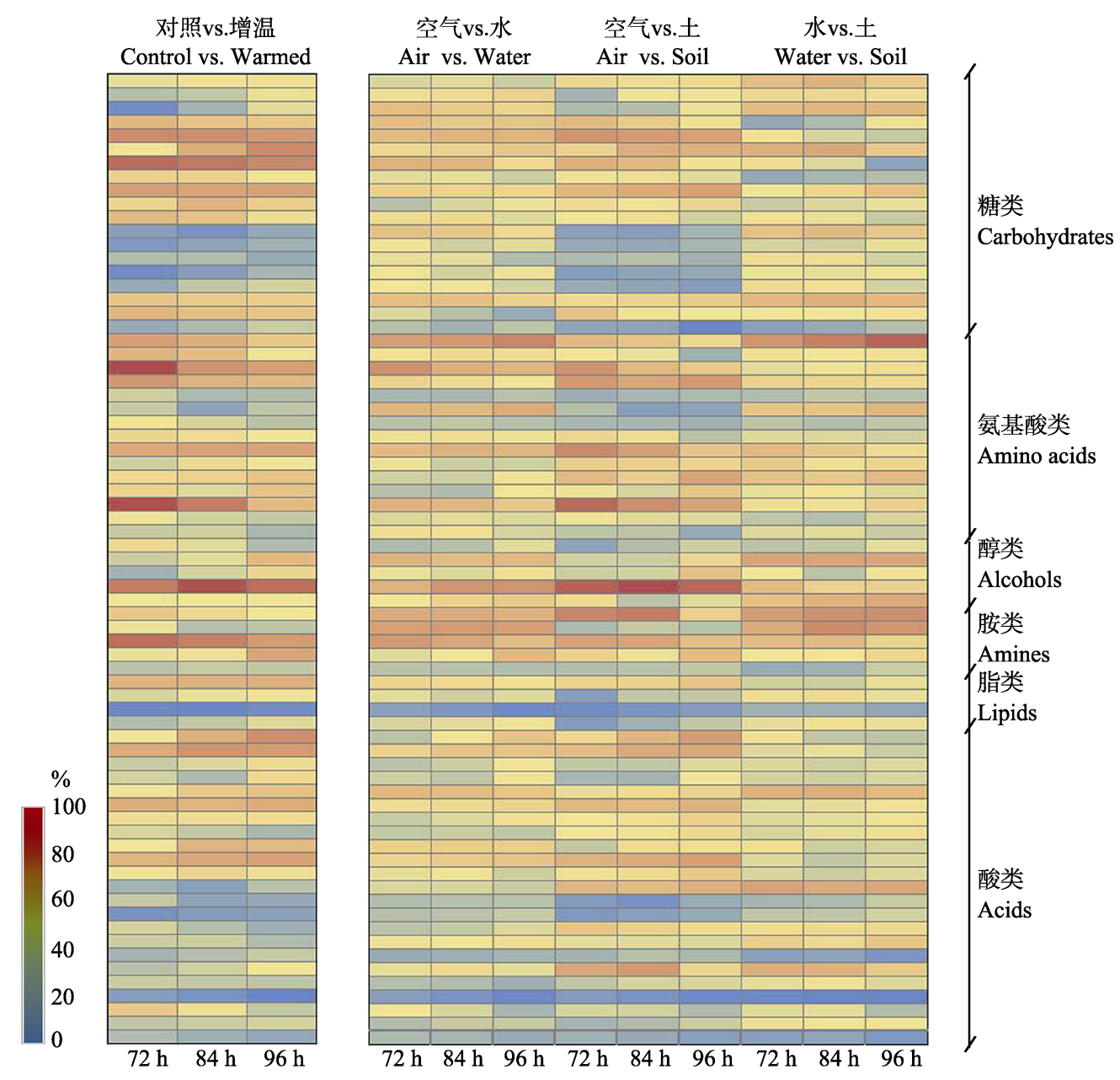

图7 相似性分析比较对照组与增温组、大气界面与水界面、大气界面与土界面、水界面与土界面的微生物碳源利用差异贡 献度热图。颜色变化(从蓝到红色)代表不同碳源对差异的相对贡献度变化(0到100\%)。观测样品为 $72-96 \mathrm{~h}$ 的碳源利用情况。

Fig. 7 Similarity analysis shows the contribution of different carbon sources to the dissimilarity between control vs. warming, air interface vs. water interface, air interface vs. soil interface, and water interface vs. soil interface, illustrated by heatmaps. The color (blue to red) represents the relative contribution of different carbon substrates $(0-100 \%)$. The observations at $72-96 \mathrm{~h}$ incubation point were used for drawing the heatmaps.

D-松二糖、肌醇以及N-乙酰-D-半乳糖胺等。造成大 气界面、水界面与土界面微生物代谢差异的关键碳 源主要为醇类和胺类碳源, 对差异贡献度最高的碳 源主要包括肌醇、N-乙酰-D-葡糖胺、L-果糖等。酸 类物质对不同处理之间代谢差异的贡献度较低, 表 明酸类物质不是造成处理之间差异的主要碳源。

\section{3 讨论}

\section{1 模拟增温对调落物分解速率的影响}

随着全球气候变暖持续加速, 增温对调落物分 解的影响逐渐成为研究热点。温度是影响调落物分 解的主要因子(Bonanomi et al., 2015), 以往相关研 究发现, 调落物的分解速率会随着温度的升高而加 快(宋飘等, 2014; 张晓宁等, 2017)。有人用模型估算
表明，温度每升高 $10{ }^{\circ} \mathrm{C}$, 调落物分解速率将增加 1.768倍(黄锦学等, 2010), 可见增温对调落物分解 有明显的促进作用。本研究表明, 在湿地生态系统 中, 增温增加了调落物的分解速率, 这与之前的研 究结果一致。但是, 调落物分解常数 $k$ 值与温度的增 加并不是正相关的(Saura-Mas et al., 2012), 其对增 温幅度具有一定的适应性。温度增加过高有时也会 降低凋落物的分解速率, 张晓宁等(2017)研究发现, 与增温 $4{ }^{\circ} \mathrm{C}$ 相比, 增温 $2{ }^{\circ} \mathrm{C}$ 条件下大气界面的调落 物分解更为彻底。因为 $4{ }^{\circ} \mathrm{C}$ 增温减少了空气湿度, 使凋落物分解缺乏必要的水分条件, 调落物分解的 温度与湿度协同促进作用在较大程度上被抑制，从 而降低了调落物的分解速率。He等(2007)在研究调 落物降解与温度的关系中也发现, 调落物的质量损 
失率在低温处理下比在高温处理下更高。可见, 调 落物分解的快慢对增温的响应是具有一定的适应范 围的。另外, 增温还会抑制调落物表面某些微生物 的生长、繁殖及群落代谢活性(Christoffer et al., 2018), 使凋落物表面微生物活动受到一定的限制, 进而降低调落物的分解。未来关于温度对湿地生态 系统中调落物分解的作用以及调落物对增温的趋同 与趋异响应机制还需要进一步探讨。

\section{2 生境差异对调落物分解速率的影响}

生境差异对调落物的分解产生重要影响(Liu et al., 2015)。有研究对比了溪流、河岸带以及林地三 种区域生境下调落物的分解特征, 发现溪流生境条 件下调落物中木质素残留质量最低(岳楷等, 2016); 而在干旱少雨地区, 处于立枯及掩埋状态的调落物 比地表的调落物分解更快(Liu et al., 2015), 表明生 境中的不同环境要素可深刻影响调落物分解过程。 不同于地形、坡度、朝向以及土壤水分等环境因素 调控陆生植物调落物分解过程, 对于湿地挺水植物 而言, 其所存在的生境主要包括立枯阶段的大气生 境、倒伏阶段的水生境和沉水阶段的土生境, 因此 湿地挺水植物调落物的分解速率主要由处于不同分 解阶段的水文环境因素调控。在大气界面, 受水分 条件限制, 同时缺乏大型底栖动物活动及冻融作用 对调落物的物理破碎过程, 导致调落物分解速率较 低。与大气界面相比, 水、土界面温暖而湿润的环 境因素更有利于调落物中酸不溶性组分等难分解的 高分子结构体的快速降解(Wu et al., 2010), 并且土 壤中含有大量的微生物, 通过与调落物直接接触, 其对底物的利用效率比大气界面更高(Hobara et al., 2014)。另外, 我们发现每到秋冬季节, 滇西北区域 水路交错地带有明显的冻融现象, 冻结作用也可以 直接破坏调落物的物理结构从而加快处于水、土界 面凋落物的分解速率(Ni et al., 2017)。可见, 由这些 生境所引起的环境因子差异是影响调落物分解的关 键(Parker et al., 2018)。

\section{3 调落物分解的微生物驱动力}

微生物是影响调落物分解过程的关键驱动力, 其对温度等环境要素的变化非常敏感(Moghadam \& Zimmer, 2014)。气候变暖情形下, 植物调落物分解 更容易受到微生物的正向调控作用, 这种正向调控 作用主要通过温度升高影响微生物生物量、群落结 构组成及其功能酶活性, 并最终影响调落物的分解
过程(宋新章等, 2008)。Moghadam和Zimmer (2014) 研究发现, 在特定环境下增温能够显著增加调落物 表面的细菌密度。本研究中, 温度主要通过改变调 落物叶际微生物的群落组成结构来影响调落物分解 过程。在对照组中, 泛菌属微生物为优势菌群。泛 菌属中的某些微生物主要分离自植物叶际, 有研究 报道分离自植物内生菌的Pantoea alhagi具有促进 小麦植株生长、抗击干旱胁迫的功能(Chen et al., 2017)。在增温条件下, 叶片表面的优势菌落转变为 动性杆菌属, 然而目前有关动性杆菌属在调落物分 解过程中的作用还未见报道。

微生物的类群数量变化与自然环境条件密切相 关(Ferreira et al., 2016), 地理位置和环境是影响调 落物叶际微生物结构功能的决定性因素(Chaudhary et al., 2017)。在水界面发现的不动杆菌属(Acinetobacter) 是一类存在于自然水体中的常见土著微生物 (Warskow \& Juni, 1972), 而在水界面、土界面发现 的假单胞菌属、沙雷氏菌属以及鞘脂单胞菌属均是 土壤、水体环境中的常见菌种(Sørensen \& Nybroe, 2004)。可见, 处于大气分解界面的调落物叶际微生 物很可能来自于植物内生菌本身, 而处于水体、土 壤分解界面的凋落物叶际微生物则主要来自于水环 境与土环境中土著微生物的侵入。尤其是在土界面, 叶际微生物与土壤直接接触, 导致调落物分解的生 物因素受土壤微生物的调控。相对于大气界面, 水、 土界面中的调落物微生物绝对数量更高、功能代谢 能力更强, 这是因为两种界面下充足的水分及营养 物质给调落物微生物提供了更加适宜的生存条件 (Veronica \& Chauvet, 2011), 而处于大气界面下的 微生物则面临着紫外线照射、温湿波动过大和存在 活性氧等不利于微生物生长的严苛条件(Wierzchos et al., 2018), 这些都给微生物的生长带来了极大的 挑战。

本文进一步通过Biolog技术研究了叶际微生物 对不同碳源的代谢情况。增温处理略微提高了碳源 代谢活性，但对照组与增温组之间的差异不显著。 在生境发生变化的情况下, 处于土壤中的叶际微生 物, 其群落绝对数量更高, 且微生物群落对 71 种碳 源的整体代谢活性显著高于其他处理。微生物群落 的功能代谢差异, 导致微生物通过各自特有的方式 影响调落物的分解、碎裂及硝化过程, 其整体代谢 活性将最终决定生态进程速率(杨万勤等, 2007)。通 
过SIMPER分析进一步发现，微生物对不同碳源代 谢活性的差异, 不仅体现在微生物对整体代谢活性 的高低, 还集中体现在微生物对不同类别、甚至单 个碳源的利用程度上(Kurten \& Barkoh, 2016)。例如 本研究发现, 醇类和胺类碳源的差异化利用是不同 处理之间微生物代谢活性趋异的主要特征, 而酸类 碳源的代谢强度在不同处理之间基本相似。微生物 在厌氧发酵过程中会产生醇类物质(张静等, 2010), 处于水、土界面的微生物对醇类碳源具有更高的利 用程度, 这可能与微生物所处的厌氧环境密切相 关。微生物群落拥有一套丰富的酶系统, 可以利用 各种类型的碳源作为底物, 分解植物组织中的复杂 化合物(孙志高和刘景双, 2007), 不同物种对功能差 异度的贡献可能是提高生态进程速率(如调落物分 解速率)的关键因素。需要注意的是, Biolog法存在 选择性培养问题, 只有能够利用微孔板碳源的菌群 才能得到反映, 它检测到的微生物群落数据不包括 休眠群体和不能利用Biolog底物的群体(郑华等, 2004), 未来应结合多种途径和方法深入研究调落 物分解速率与微生物群落功能的关系, 从而获得更 全面的结果。

\section{4 结论}

本文分析了湿地生态系统中的挺水植物叶调落 物在增温处理及不同生境条件下的分解速率差异, 揭示了不同处理之间调落物叶际微生物的绝对数 量、组成多样性及功能代谢活性等微生物群落特征。 主要结论为:

(1)经过一年的分解, 在增温实验中对照组荠草 的质量残留率为 $77.7 \%$, 增温组的质量残留率为 $66.4 \%$, 模拟增温略微提高了调落物的分解速率。同 时, 在生境差异实验中荠草在大气界面的残留率为 $77.7 \%$, 水界面的残留率为 $42.4 \%$, 在土界面的残留 率仅为 $25.3 \%$, 不同生境所代表的环境因子差异对 调落物分解的影响更为突出。

(2)模拟增温主要影响湿地挺水植物凋落物叶 际微生物的群落结构组成。生境差异主要影响湿地 挺水植物叶际微生物的绝对数量、微生物多样性、 群落结构组成以及功能代谢活性。处于土界面的叶 际微生物, 其微生物数量、多样性及碳源代谢活性 显著高于处于水、大气界面中的微生物, 是土界面 调落物快速分解的关键驱动力。

\section{参考文献}

Berg B, McClaugherty C (1989). Nitrogen and phosphorus release from decomposing litter in relation to the disappearance of lignin. Canadian Journal of Botany, 67, $1148-1156$.

Bonanomi G, Capodilupo M, Incerti G, Mazzoleni S (2015). Litter quality and temperature modulate microbial diversity effects on decomposition in model experiments. Community Ecology, 16, 167-177.

Caporaso JG, Kuczynski J, Stombaugh J, Bittinger K, Bushman FD, Costello KE, Fierer N, Pena AG, Goodrich JK, Gordon JI, Huttley GA, Kelly ST, Knights D, Koening JE, Ley RE, Lozupone GA, McDonald D, Muegge BD, Pirrung M, Reeder J, Sevinsky JR, Turnbaugh PJ, Walters WA, Widmann J, Yatsunenko T, Zaneveld J, Rob K (2010). QIIME allows analysis of high-throghput community sequencing data. Nature, 7, 335-336.

Chaudhary D, Kumar R, Sihag K, Rashmi \& Kumari A (2017). Phyllospheric microflora and its impact on plant growth: A review. Agricultural Reviews, 38, 51-59.

Chen C, Xin K, Liu H, Cheng J, Shen XH, Wang Y, Zhang L (2017). Pantoea alhagi, a novel endophytic bacterium with ability to improve growth and drought tolerance in wheat. Scientific Reports, 7, 41564. DOI: 10.1038/srep41564.

Chen YM, He RL, Deng CC, Yang WQ, Zhang J, Yang L, Liu Y (2015). Litter decomposition and lignocellulose enzyme activities of Actinothuidium hookeri and Cystopteris montana in alpine timberline ecotone of Western Sichuan, China. Chinese Journal of Applied Ecology, 26, 3251-3258. [陈亚梅, 和润莲, 邓长春, 杨万勤, 张健, 杨林, 刘洋 (2015). 川西高山林线交错带两种地被物分 解的木质纤维素酶活性特征. 应用生态学报, 26 , 3251-3258.]

Christoffer B, Mireia BF, Jarone P, Catherine L (2018). Response of microbial communities to changing climate conditions during summer cyanobacterial blooms in the Baltic Sea. Frontiers in Microbiology, 9, 1562. DOI: 10.3389/ fmicb.2018.01562.

Fan ZX, Bräuning A, Thomas A, Li JB, Cao KF (2011). Spatial and temporal temperature trends on the Yunnan Plateau (Southwest China) during 1961-2004. International Journal of Climatology, 31, 2078-2090.

Ferreira V, Raposeiro PM, Pereira A, Cruz AM, Costa AC, Graca M, Goncalves V (2016). Leaf litter decomposition in remote oceanic island streams is driven by microbes and depends on litter quality and environmental conditions. Freshwater Biology, 61, 783-799.

Guo XH, Xiao DR, Tian K, Yu HZ (2013). Biomass production and litter decomposition of lakeshore plants in Napahai wetland, Northwestern Yunnan Plateau, China. Acta Ecologica Sinica, 33, 1425-1432. [郭绪虎, 肖德荣, 田

www.plant-ecology.com 
昆, 余红忠 (2013). 滇西北高原纳帕海湿地湖滨带 优势植物生物量及其调落物分解. 生态学报, 33 , 1425-1432.]

He XB, Song FQ, Zhang P, Lin YH, Tian XJ, Ren LL, Chen CL, Xiao N, Tan HX (2007). Variation in litter decompositiontemperature relationships between coniferous and broadleaf forests in Huangshan Mountain, China. Journal of Forestry Research, 18, 291-297.

Hobara S, Osono T, Hirose D, Noro K, Hirota M, Benner R (2014). The roles of microorganisms in litter decomposition and soil formation. Biogeochemistry, 118, 471-486.

Huang JX, Huang LM, Lin ZC, Chen GS (2010). Controlling factors of litter decomposition rate in China's forests. Journal of Subtropical Resources and Environment, 5(3), 56-63. [黄锦学, 黄李梅, 林智超, 陈光水 (2010). 中国 森林调落物分解速率影响因素分析. 亚热带资源与环 境学报, 5(3), 56-63.]

IPCC (Intergovernmental Panel on Climate Change)(2013). Climate Change 2013: The Physical Science Basis. Cambridge University Press, Cambridge, UK.

Kuehn KA, Steiner D, Gessner MO (2004). Diel mineralization patterns of standing-dead plant litter: Implications for $\mathrm{CO}_{2}$ flux from wetlands. Ecology, 85, 2504-2518.

Kurten GL, Barkoh A (2016). Evaluation of community-level physiological profiling for monitoring microbial community function in aquaculture ponds. North American Journal of Aquaculture, 78, 34-44.

Li Q, Zhou DW, Chen XY (2014). The accumulation, decomposition and ecological effects of above-ground litter in terrestrial ecosystem. Acta Ecologica Sinica, 34, 3807-3819. [李强, 周道玮, 陈笑莹 (2014). 地上枯落 物的累积、分解及其在陆地生态系统中的作用. 生态学 报, 34, 3807-3819.]

Li SS, Wang ZW, Yang JJ (2016). Changes in soil microbial communities during litter decomposition. Biodiversity Science, 24, 195-204. [李姗姗, 王正文, 杨俊杰 (2016). 调落物分解过程中土壤微生物群落的变化. 生物多样 性, 24, 195-204.]

Liu GF, Cornwell WK, Pan X, Ye D, Liu FH, Huang ZY, Dong M, Cornelissen JH (2015). Decomposition of 51 semidesert species from wide-ranging phylogeny is faster in standing and sand-buried than in surface leaf litters: Implications for carbon and nutrient dynamics. Plant and Soil, 396, 175-187.

Marty C, Houle D, Gagnon C (2015). Variation in stocks and distribution of organic $\mathrm{C}$ in soils across 21 eastern Canadian temperate and boreal forests. Forest Ecology and Management, 345, 29-38.

Moghadam FS, Zimmer M (2014). Effects of warming and nutrient enrichment on how grazing pressure affects leaf litter-colonizing bacteria. Journal of Environment Quality, $43,851-858$.
Newell SY (2001). Fungal biomass and productivity in standing-decaying leaves of black needlerush (Juncus roemerianus). Marine \& Freshwater Research, 52, 249-255.

Ni XY, Yang WQ, Li H, Xu LY, He J, Tan B, Wu FZ (2017). The responses of early foliar litter humification to reduced snow cover during winter in an alpine forest. Canadian Journal of Science, 94, 453-461.

Parker TC, Sanderman J, Holden RD, Blume-Werry G, Sjogersten S, Large D, Castro-Diaz M, Street LE, Subke JA, Wookey PA (2018). Exploring drivers of litter decomposition in a greening Arctic: Results from a transplant experiment across a tree-line. Ecology, 99, 2284-2294.

Peng SL, Liu Q (2002). The dynamics of forest litter and its responses to global warming. Acta Ecologica Sinica, 22, 1534-1544. [彭少麟, 刘强 (2002). 森林调落物动态及 其对全球变暖的响应. 生态学报, 22, 1534-1544.]

Saura-Mas S, Estiarte M, Peñuelas J, Lloret F (2012). Effects of climate change on leaf litter decomposition across post-fire plant regenerative groups. Environmental \& Experimental Botany, 77, 274-282.

Song P, Zhang NL, Ma KP, Guo JX (2014). Impacts of global warming on litter decomposition. Acta Ecologica Sinica, 34, 1327-1339. [宋飘, 张乃莉, 马克平, 郭继勋 (2014). 全球气候变暖对调落物分解的影响. 生态学报, 34 , 1327-1339.]

Song XZ, Jiang H, Zhang HL, Yu SQ, Zhou GM, Ma YD, Chang SX (2008). A review on the effects of global environment change on litter decomposition. Acta Ecologica Sinica, 28, 4414-4423. [宋新章, 江洪, 张慧玲, 余树全, 周国模, 马元丹, Scott X. Chang (2008). 全球环境变化 对森林调落物分解的影响. 生态学报, 28, 4414-4423.]

Song Y, Gu XR, Yan HY, Mao WT, Wu XL, Wan YX (2014). Dynamics of microbes and enzyme activities during litter decomposition of Pinus Massoniana forest in midsubtropical area. Environmental Science, 35, 1151-1158. [宋影, 古夕容, 严海元, 毛文蹈, 吴雪莲, 万宇轩 (2014). 中亚热带马尾松林调落物分解过程中的微生物 与酶活性动态. 环境科学, 35, 1151-1158.]

Sørensen J, Nybroe O (2004). Pseudomonas. Springer, Boston, USA. 303-324.

Sun ZG, Liu JS (2007). Development in study of wetland litter decomposition and its responses to global change. Acta Ecologica Sinica, 27, 1606-1618. [孙志高, 刘景双 (2007). 湿地枯落物分解及其对全球变化的响应. 生态 学报, 27, 1606-1618.]

Tang SS, Yang WQ, Yin R, Xiong L, Wang HP, Wang B, Zhang Y, Peng YJ, Chen QS (2014). Spatial characteristics in decomposition rate of foliar litter and controlling factors in Chinese forest ecosystems. Chinese Journal of Plant Ecology, 38, 529-539. [唐仕姗, 杨万勤, 殷睿, 熊莉, 王 海鹏, 王滨, 张艳, 彭艳君, 陈青松 (2014). 中国森林 生态系统调落叶分解速率的分布特征及其控制因子. 
植物生态学报, 38, 529-539.]

Veronica F, Chauvet E (2011). Future increase in temperature more than decrease in litter quality can affect microbial litter decomposition in streams. Oecologia, 167, 279-291.

Wang FY (1989). Forest litter quality research review. Advances in Ecology, 2, 82-89. [王凤友 (1989). 森林调落 量研究综述. 生态学进展, 2, 82-89.]

Wang YH, Gong JR, Liu M, Huang YM, Yan X, Zhang ZY, Xu S, Luo QP (2015). Effects of grassland-use on soil respiration and litter decomposition. Chinese Journal of Plant Ecology, 39, 239-248. [王忆慧, 龚吉芯, 刘敏, 黄永梅, 晏欣, 张梓瑜, 徐沙, 罗亲普 (2015). 草地利用方式对 土壤呼吸和调落物分解的影响. 植物生态学报, 39 , 239-248.]

Wang Z, Cao GQ, Zhang YQ, Zhang HY, Wang F, Chen AL (2017). Responses of metabolism diversity of topsoil microbial to the litterfall addition in Cunninghamia laneolata plantation. Journal of Forest and Environment, 37, 148-154. [王珍, 曹光球, 张月全, 张海燕, 王飞, 陈爱 玲 (2017). 调落物配比对杉木土壤微生物碳代谢多样 性的影响. 森林与环境学报, 37, 148-154.]

Warskow AL, Juni E (1972). Nutritional requirements of Acinetobacter strains isolated from soil, water, and sewage. Journal of Bacteriology, 112, 1014-1016.

Wierzchos J, Casero MC, Artieda O, Ascaso C (2018). Endolithic microbial habitats as refuges for life in polyextreme environment of the Atacama Desert. Current Opinion in Microbiology, 43, 124-131.

Wu FZ, Yang WQ, Zhang J, Deng RJ (2010). Litter decomposition in two subalpine forests during the freeze-thaw season. Acta Oecologica, 36, 135-140.

$\mathrm{Xu}$ XF, Tian HQ, Wan SQ (2007). Climate warming impacts on carbon cycling in terrestrial ecosystems. Journal of Plant Ecology (Chinese Version), 31, 175-188. [徐小峰, 田汉勤, 万师强 (2007). 气候变暖对陆地生态系统碳循 环的影响. 植物生态学报, 31, 175-188.]

Xu ZF, Yin HJ, Zhao CZ, Cao G, Wan ML, Liu Q (2009). A review of response of litter decomposition in terrestrial ecosystems to global warming. Journal of Plant Ecology, 33，1208-1219. [徐振锋, 尹华军, 赵春章, 曹刚, 万名 利, 刘庆 (2009). 陆地生态系统调落物分解对全球气候 变暖的响应. 植物生态学报, 33, 1208-1219.]
Yang WQ, Deng RJ, Zhang J (2007). Forest litter decomposition and its responses to global climate change. Chinese Journal of Applied Ecology, 18, 2889-2895. [杨万勤, 邓 仁菊, 张健 (2007). 森林凋落物分解及其对全球气候变 化的响应. 应用生态学报, 18, 2889-2895.]

Yang XH, Peng LJ, Li SY, Wang SZ (2013). Effect of mangrove leaf litter decomposition on soil dissolved organic matter. Ecology and Environmental Sciences, 22, 924-930. [杨秀虹, 彭琳婧, 李适宇, 王诗忠 (2013). 红树植物调 落叶分解对土壤可溶性有机质的影响. 生态环境学报, 22, 924-930.]

Yue K, Yang WQ, Peng Y, Huang CP, Zhang C, Wu FZ (2016). Effects of streams on lignin degradation during foliar litter decomposition in an alpine forest. Chinese Journal of Plant Ecology, 40, 893-901. [岳楷, 杨万勤, 彭艳, 黄春萍, 张川, 吴福忠 (2016). 高寒森林溪流对 调落叶分解过程中木质素降解的影响. 植物生态学报, 40, 893-901.]

Zhang J, Zhai FF, Zhang JH, Sun FB, Zhang HJ, Mao ZG (2010). The behavior of anaerobic fermentation in the technique of alcohol fermentation cooperate with methane fermentation. Journal of Food Science \& Biotechnology, 29, 276-281. [张静, 翟芳芳, 张建华, 孙付保, 张宏健, 毛忠贵 (2010). 酒精沼气双发酵偶联中厌氧沼气的发 酵行为. 食品与生物技术学报, 29, 276-281.]

Zhang XN, Liu ZY, Li LP, Wang H, Zhang Y, Sun M, Xiao DR (2017). Effect of experimental warming on the decomposition of litter from dominant lakeside plants in a typical wetland of Northwestern Yunnan Plateau, China. Acta Ecologica Sinica, 37, 7811-7820. [张晓宁, 刘振亚, 李丽萍, 王行, 张㣱, 孙梅, 肖德荣 (2017). 大气增温 对滇西北高原典型湿地湖滨带优势植物调落物质量衰 减的影响. 生态学报, 37, 7811-7820.]

Zheng H, Ouyang ZY, Fang ZG, Zhao TQ (2004). Application of BIOLOG to study on soil microbial community functional diversity. Acta Pedologica Sinica, 41, 456-461. [郑 华, 欧阳志云, 方治国, 赵同谦 (2004). BIOLOG在土 壤微生物群落功能多样性研究中的应用. 土壤学报, 41 , 456-461.] 